\title{
Reliability and Validity of the Korean Version of the General-Food Craving Questionnaire-Trait for Children
}

\author{
Jo-Eun Jeong ${ }^{1}$, Dong-Jin Jung', Minjung Kwak¹, Hae Kyung Yang², \\ Sun-Young Lim ${ }^{3}$, Jin-Hee Lee ${ }^{3}$, Kun-Ho Yoon ${ }^{2}$, and Dai-Jin Kim ${ }^{1}$ \\ 1'Department of Psychiatry, Seoul St. Mary's Hospital, College of Medicine, The Catholic University of Korea, Seoul, Republic of Korea \\ ${ }^{2}$ Division of Eudocrinology and Metabolism, Department of Internal Medicine, Seoul St. Mary's Hospital, College of Medicine, \\ The Catholic University of Korea, Seoul, Republic of Korea \\ ${ }^{3}$ Catholic Institute of U-Healthcare, College of Medicine, The Catholic University of Korea, Seoul, Republic of Korea
}

Objective The General-Food Craving Questionnaire-Trait (G-FCQ-T) is a validated, assessment scale for food craving. The aim of this study was to measure its reliability and validity for Korean children.

Methods A total of 172 children (94 boys and 78 girls) were selected to fill out a set of questionnaires, including the G-FCQ-T, the Children's version of the Dutch Eating Behavior Questionnaire (DEBQ-C), and the Three-Factor Eating Questionnaire (TFEQ) in the Korean language.

Results The internal consistency (Cronbach's alpha $=0.933)$ and test-retest reliability $(r=0.653)$ were satisfactory. The G-FCQ-T showed a significantly positive correlation with the DEBQ-C ( $r=0.560)$ and the TFEQ ( $r=0.397)$. The optimum cutoff score of the G-FCQ-T set by Receiver Operating Characteristics analysis was 51, with sensitivity and specificity of 0.833 and 0.825 , respectively, for children.

Conclusion The G-FCQ-T showed good reliability and validity for assessing food craving for children and could become a practial instrument in clinical and research settings.

Psychiatry Investig 2017;14(5):595-602

Key Words Craving, Scale, Validation studies.

\section{INTRODUCTION}

"Craving" represents a strong motivational state and is defined in the dictionary as an intense desire or longing. ${ }^{1}$ In a similar vein, food craving is most often deemed as an intense urge to eat a certain food that is hard to stand up. ${ }^{2}$ Food craving is a matter of general experience among people and the prevalence of food craving ranges from $52 \%$ to $97 \%$ in previous reports. $^{3}$

Received: August 29, 2016 Revised: October 3, 2016

Accepted: October 8, 2016 Available online: June 16, 2017

$\triangle$ Correspondence: Dai-Jin Kim, MD, PhD

Department of Psychiatry, Seoul St. Mary's Hospital, College of Medicine, The Catholic University of Korea, 222 Banpo-daero, Seocho-gu, Seoul 06591, Republic of Korea

Tel: +82-2-2258-6933, Fax: +82-2-594-3870, E-mail: kdj922@chollian.net

$\triangle$ Correspondence: Kun-Ho Yoon, MD, PhD

Division of Eudocrinology and Metabolism, Department of Internal Medicine, Seoul St. Mary's Hospital, College of Medicine, The Catholic University of Korea, 222 Banpo-daero, Seocho-gu, Seoul 06591, Republic of Korea Tel: +82-2-2258-6007, Fax: +82-2-2258-8297, E-mail: yoonk@catholic.ac.kr

(a) This is an Open Access article distributed under the terms of the Creative Commons Attribution Non-Commercial License (http://creativecommons.org/licenses/bync/4.0) which permits unrestricted non-commercial use, distribution, and reproduction in any medium, provided the original work is properly cited.
Several studies reported that food craving has been linked to future food consumption ${ }^{4,5}$ and a previous study demonstrated that high food cravers had stronger automatic approach inclinations for food compared to low food cravers. ${ }^{6}$ Furthermore, food craving is related to body weight ${ }^{2}$ and may be clinically associated with obesity. ${ }^{1}$ In obese people, it has been linked to the body mass index (BMI), the number of lifetime weight loss attempts, and the frequency of dropouts from obesity treatments. ${ }^{7}$ That is, obese or overweight adults show more food craving than normal or underweight adults do. ${ }^{8}$

Obesity in childhood is associated with adverse health consequences such as glucose intolerance and hyperlipidemia and predicts adult obesity. ${ }^{9}$ Although, it is still not well known whether food craving differs depending on age, a previous neuroimaging study reported that adolescents showed increased ventral striatum activation in response to food compared with adults. ${ }^{10}$ The ventral striatum is a part of the brain reward system and a few studies have indicated that heightened activity in this area was associated with the craving process. ${ }^{11}$ Another study also showed that children experience stronger craving, greater striatal recruitment, less prefrontal activity, and less fron- 
tostriatal coupling than adults. ${ }^{12}$ These findings imply that targeting subjective craving responses to food may be an important treatment element for subsequent weight gain and obesity.

However, people vary in the frequency, intensity, and types of food craving, so it is difficult to understand what exactly a food craving is. In the current conceptualization, food craving is assumed to be a complex phenomenon as it includes physiological, cognitive, emotional, and behavioral factors. ${ }^{2,13,14}$

The most frequently used tools for assessing food craving are the Food Craving Questionnaires (FCQ) ${ }^{14} \mathrm{~A}$ trait of food craving that are consistent and long lasting characteristics across times and situations can be evaluated FCQ-Trait (FCQ-T). ${ }^{15}$ The FCQ-T is a self-report questionnaire, that was developed from above-mentioned viewpoint of the multidimensionality of food craving, and is sensitive to weight-loss treatment changes in obese individuals. ${ }^{16}$ The FCQ-T was later modified to measure a general index of trait food craving (General FCQ-T, G-FCQ-T) instead of a specific food craving. ${ }^{2}$

As previously mentioned, childhood is a sensitive period for the acquisition of obesity. ${ }^{17}$ To assess food craving in children could be useful for the investigation of the characteristics of children's general food consumption and cravings compared to adults and may be help to predict susceptibility to obesity including further adult obesity and weight-loss treatment success. There are a few instruments, such as the Children's version of the Dutch Eating Behavior Questionnaire (DEBQ-C) to measure children's eating styles that may contribute to or attenuate the development of overweight status. ${ }^{18}$ Nonetheless, to our knowledge, there is no instrument to evaluate children's eating behavior targeted especially at food craving. Therefore, the purposes of the present study were to evaluate the G-FCQ-T's reliability and validity for children while maintaining its basic structure.

\section{METHODS}

\section{Study design and setting}

This was a cross-sectional study of 5th grade students from an elementary school in Chung-ju city in South Korea. These students were approached from April 2015 to May 2015. Participants were 172 children ( 94 boys and 78 girls) with a mean age of 10.3 years $(\mathrm{SD}=0.5)$. This study was approved by the Institutional Review Board of Seoul St. Mary's Hospital (IRB number: KIRB-00512-21-003).

\section{Procedure}

\section{Stage 1}

The authors acquired the English version of the G-FCQ-T from Nijs et $\mathrm{al}^{2}{ }^{2}$ with permission. The G-FCQ-T scales were translated into Korean by two bilingual language psychiatrists, and modified to be adapted to young students, employing understandable sentences. Then a back translation was carried out by a third bilingual psychiatrist and the back-translated version was reviewed.

\section{Stage 2}

Each student and parent received an explanation of the purpose of the study. Parental consent was obtained for all participants. The students were administered the following questionnaires: the G-FCQ-T (1st G-FCQ-T), DEBQ-C, and ThreeFactor Eating Questionnaire (TFEQ). The questionnaires were given under the supervision of a researcher and a teacher at the school. The researcher helped with reading if necessary.

In addition, weight and height were measured and BMI was calculated. To determine whether a student was underweight (BMI $<5$ th percentile), normal weight (5th-84th percentile), overweight (85th-94th percentile), or obese (BMI $\geq 95$ th percentile), we used international cut-off scores. ${ }^{19}$

\section{Stage 3}

A month after completing the first set of questionnaires (1st G-FCQ-T, DEBQ-C, and TFEQ), the 172 students were requested to complete the G-FCQ-T (2nd G-FCQ-T) scale for a second time.

\section{Instruments}

\section{G-FCQ-T}

The G-FCQ-T was developed to assess a general urge to eat and measures characteristics of food craving as a trait. The G-FCQ-T is a self-report scale with 21 items and each question has a 6-point Likert scale ranging from 1 to $6(1=$ never to $6=$ always). The higher the total score is, the greater the degree of food craving. The scale contains four subdomains: 1) preoccupation with food, to assess obsessive thinking about food or eating (6 items), 2) loss of control, which is difficulty stopping eating when exposed to food cues (6 items), 3) positive outcome expectancy, to assess the extent of the expectation that eating will provide positive or negative reinforcement ( 5 items), and 4) emotional craving for food when experiencing negative emotions (4 items). The G-FCQ-T has demonstrated acceptable internal consistency with a Cronbach's a coefficient of 0.90 and construct validity in previous work. ${ }^{2}$

\section{DEBQ-C ${ }^{18}$}

The DEBQ-C is a 20-item measure of three types of eating behavior for children, namely emotional (7-items), external (6-items), and restrained eating (7-items). Items in the emotional eating subscale assess the proneness to overeat in response 
to negative emotional states. Items in the external eating subscale assess the proneness to overeat in response to food-related cues. Additionally, items in the restrained eating subscale assess the proneness to restrict food for weight control. The DEBQ-C allows three-choice responses of no (1), sometimes (2), or yes (3). In samples of 7- to 12-year-olds, Cronbach's alpha ranged from 0.73 to $0.82 .{ }^{18}$ In this study's sample, Cronbach's alpha was $0.862,0.945,0.828$, and 0.886 for total DEBQ-C, emotional, external, and restrained eating, respectively.

\section{TFEQ $^{20}$}

This scale is for prediction of eating behaviors. The TFEQ is made up 3 factors that assess a person's attitude toward eating. 1) Cognitive restraints of eating (21-items) reflects the tendency of some persons to cognitively control eating behavior and behaviorally restrain food intake in order to regulate their body weight. 2) Disinhibition of eating control (16-items) refers to personal differences in loss of inhibition of eating. 3) Susceptibility to hunger (14-items) reflects the subjective feeling of hunger and its behavioral consequences. The Cronbach's alpha was $0.820 .{ }^{21}$ In the current study, Cronbach's alpha was 0.809 for the total score and ranged from 0.621 to 0.803 for the subscales.

\section{Statistical analysis}

All analyses were conducted using the Statistical Package for the Social Sciences version 21.0 (IBM Corp., Armonk, NY, USA).

The internal consistencies of the G-FCQ-T and its subscales were evaluated by measuring Cronbach's alpha coefficients. The test-retest reliability was assessed by means of Pearson correlation coefficient.

Pearson's correlation was used to investigate the construct validity of the G-FCQ-T by examining relationships with the DEBQ-C and TFEQ.

The sensitivity, specificity, and area under the curve (AUC) were calculated and to find optimal cutoff points to predict high food cravers, receiver operating characteristic (ROC) analysis was applied to all participants dependent on the sum of emotional and external eating scales of DEBQ-C at the mean+2SD (standard deviation).

Exploratory principal component analysis with varimax rotation was performed on the G-FCQ-T.

\section{RESULTS}

Demographics and clinical characteristics (Table 1)

The percentage of people with 1) underweight, 2) normal weight, 3) overweight, and 4) obesity was 5.3, 64.9, 14.0, and $15.8 \%$, respectively. No difference was seen in the BMI distribution between males and females. The mean total score of the 1st G-FCQ-T, DEBQ-C, TFEQ, and 2nd G-FCQ-T was $38.7,31.2,13.1$, and 37.8, respectively. There were no gender differences in total or subdomain scores of 1 st G-FCQ-T, DEBQ-C, TFEQ, and 2nd G-FCQ-T except for subscale scores of TFEQ cognitive control (12.9 \pm 3.7 in male, $14.0 \pm 4.3$ in female, $\mathrm{p}<0.05$ ) (data not shown). Only the DEBQ-C total (a, $\mathrm{b}<\mathrm{d})$ and DEBQ-C restrained eating subscale $(\mathrm{a}, \mathrm{b}<\mathrm{c}, \mathrm{d})$, TFEQ total $(\mathrm{a}, \mathrm{b}<\mathrm{d})$, TFEQ cognitive restraints subscale $(\mathrm{a}, \mathrm{b}<\mathrm{d})$, and TFEQ disinhibition subscale $(b<d)$ scores showed significant differences between the BMI groups in the total or subdomain scores of the 1st G-FCQ-T, DEBQ-C, TFEQ, and 2nd G-FCQ$\mathrm{T}$ (not shown).

\section{Internal consistency and test-retest reliability}

(Table 2, Figure 1)

In 172 participants, the Cronbach's a coefficient was 0.933

Table 1. Characteristics of the study population $(\mathrm{N}=172)$

\begin{tabular}{|c|c|c|}
\hline Variables & Mean (SD) & $\mathrm{N}(\%)$ \\
\hline Age (years) & $10.3(0.5)$ & \\
\hline \multicolumn{3}{|l|}{ Gender } \\
\hline Male & & $94(54.7)$ \\
\hline Female & & $78(45.3)$ \\
\hline BMI & $19.8(4.3)$ & \\
\hline Underweight (a) & & $9(5.3)$ \\
\hline Normal weight (b) & & $111(64.9)$ \\
\hline Overweight (c) & & $24(14.0)$ \\
\hline Obesity (d) & & $27(15.8)$ \\
\hline 1st G-FCQ-T & $38.7(16.5)$ & \\
\hline Preoccupation with food & $9.4(4.6)$ & \\
\hline Loss of control & $11.3(5.5)$ & \\
\hline Positive outcome expectancy & $11.4(5.6)$ & \\
\hline Emotional craving & $6.1(3.0)$ & \\
\hline DEBQ-C & $31.2(6.7)$ & \\
\hline Emotional eating & $8.5(2.8)$ & \\
\hline External eating & $9.3(3.0)$ & \\
\hline Restrained eating & $13.4(4.0)$ & \\
\hline TFEQ & $13.1(5.6)$ & \\
\hline Cognitive restraints & $6.8(3.7)$ & \\
\hline Disinhibition & $3.9(1.7)$ & \\
\hline Susceptibility to Hunger & $2.4(2.4)$ & \\
\hline 2nd G-FCQ-T & $37.8(15.3)$ & \\
\hline Preoccupation with food & $9.1(3.7)$ & \\
\hline Loss of control & $11.2(5.4)$ & \\
\hline Positive outcome expectancy & $10.8(5.3)$ & \\
\hline Emotional craving & $6.3(3.0)$ & \\
\hline
\end{tabular}

G-FCQ-T: General-Food Craving Questionnaire-Trait, DEBQ-C: Children's version of the Dutch Eating Behavior Questionnaire, TFEQ: Three-Factor Eating Questionnaire 
for G-FCQ-T. The single item-total correlation coefficients ranged from 0.54 to 0.74 (Table 2 ). The test-retest reliability was measured after a 1-month interval. Cronbach's $\alpha$ after a 1 -month interval was 0.925 . The correlation coefficient of the G-FCQ-T total scores in the 2 trials was 0.653 and showed good test-retest reliability $(\mathrm{p}<0.001)$ (Figure 1$)$.

\section{Construct validity (Table 3 )}

To assess construct validity, we compared the G-FCQ-T with the DEBQ-C and TFEQ. The correlation coefficients were $0.560(\mathrm{p}<0.01)$ and $0.397(\mathrm{p}<0.01)$ for G-FCQ-T total score with DEBQ-C and TFEQ total score, respectively. There were more considerable correlations between G-FCQ-T and DEBQ-C scores than between G-FCQ-T and TFEQ scores. The G-FCQ-T total and all 4 subdomain scores were related to the DEBQ-C emotional eating and external eating subscale scores, but no significant correlation between the G-FCQ-T and DEBQ-C restrained eating subscale was found. Further, G-FCQ-T scores were also related to the TFEQ disinhibition and susceptibility to hunger subscales, but no significant correlation between the G-FCQ-T and TFEQ cognitive restraints subscale was found. In addition, the strongest correlations were shown between the DEBQ-C emotional eating and G-FCQ-T emotional craving subscale, and between the DEBQ-C external eating and G-FCQ-T loss of control subscale.

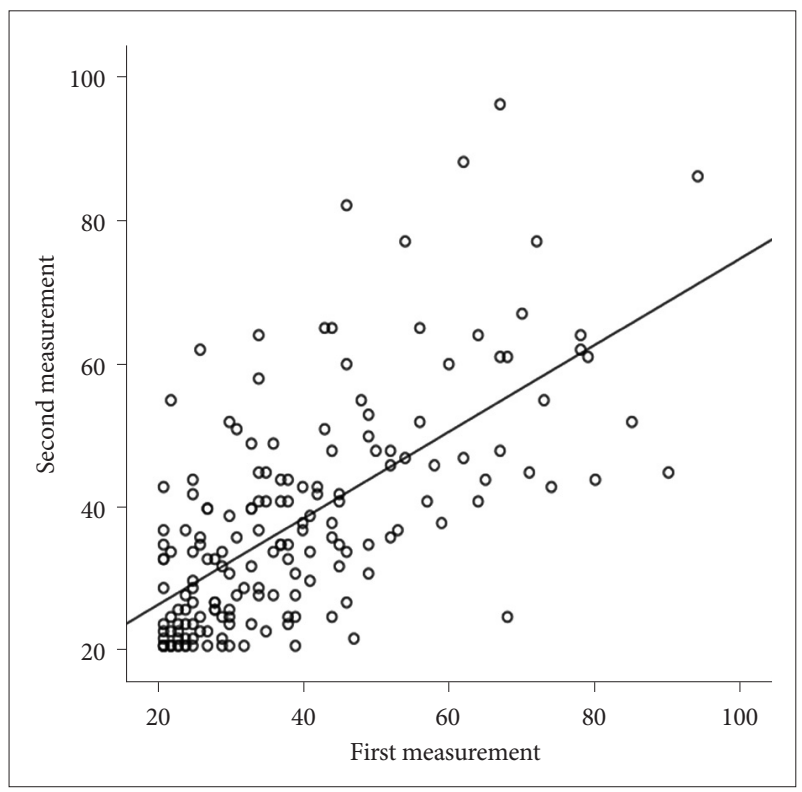

Figure 1. Scatterplot showing the correlation between scores on the G-FCQ-T between the two measurements $(r=0.653, p<0.01)$. G-FCQ-T: General-Food Craving Questionnaire-Trait.

Table 2. Corrected item-total correlations and Cronbach's alpha if item was deleted for the G-FCQ-T

\begin{tabular}{|c|c|c|c|c|}
\hline Item & Scale mean if item deleted & Scale variance if item deleted & Corrected item-total correlation & Cronbach's alpha if item deleted \\
\hline 1 & 36.72 & 246.343 & 0.660 & 0.928 \\
\hline 2 & 36.81 & 245.568 & 0.627 & 0.929 \\
\hline 3 & 36.64 & 243.764 & 0.621 & 0.929 \\
\hline 4 & 36.61 & 246.953 & 0.575 & 0.930 \\
\hline 5 & 37.10 & 247.591 & 0.719 & 0.928 \\
\hline 6 & 36.78 & 243.998 & 0.690 & 0.928 \\
\hline 7 & 37.17 & 254.928 & 0.535 & 0.931 \\
\hline 8 & 37.07 & 248.276 & 0.705 & 0.932 \\
\hline 9 & 36.72 & 244.495 & 0.623 & 0.929 \\
\hline 10 & 37.34 & 257.958 & 0.542 & 0.931 \\
\hline 11 & 37.30 & 254.107 & 0.687 & 0.929 \\
\hline 12 & 37.40 & 258.019 & 0.605 & 0.930 \\
\hline 13 & 37.29 & 251.435 & 0.687 & 0.928 \\
\hline 14 & 36.94 & 249.125 & 0.584 & 0.930 \\
\hline 15 & 36.63 & 243.136 & 0.618 & 0.929 \\
\hline 16 & 35.95 & 243.301 & 0.548 & 0.932 \\
\hline 17 & 36.04 & 238.940 & 0.578 & 0.931 \\
\hline 18 & 36.66 & 243.116 & 0.637 & 0.929 \\
\hline 19 & 37.22 & 253.354 & 0.600 & 0.930 \\
\hline 20 & 37.31 & 256.252 & 0.611 & 0.930 \\
\hline 21 & 37.17 & 250.644 & 0.736 & 0.928 \\
\hline
\end{tabular}

G-FCQ-T: General-Food Craving Questionnaire-Trait 
Table 3. Construct validity of G-FCQ-T (Pearson's correlation): subscales of the G-FCQ-T and the DEBQ-C and TFEQ

\begin{tabular}{|c|c|c|c|c|c|}
\hline & \multicolumn{5}{|c|}{ G-FCQ-T } \\
\hline & Preoccupation with food & Loss of control & Positive outcome expectancy & Emotional craving & Total \\
\hline \multicolumn{6}{|l|}{$\overline{\mathrm{DEBQ}}-\mathrm{C}$} \\
\hline Total & $0.482^{*}$ & $0.451^{*}$ & $0.463^{*}$ & $0.585^{*}$ & $0.560^{*}$ \\
\hline Emotional eating & $0.411^{*}$ & $0.317^{*}$ & $0.350^{*}$ & $0.589^{*}$ & $0.449^{*}$ \\
\hline External eating & $0.586^{*}$ & $0.622^{*}$ & $0.571^{*}$ & $0.577^{*}$ & $0.682^{*}$ \\
\hline Restrained eating & 0.083 & 0.070 & 0.106 & 0.137 & 0.117 \\
\hline \multicolumn{6}{|l|}{ TFEQ } \\
\hline Total & $0.396^{*}$ & $0.375^{*}$ & $0.302^{*}$ & $0.278^{*}$ & $0.397 *$ \\
\hline Cognitive restraints & 0.011 & 0.009 & 0.047 & 0.013 & 0.031 \\
\hline Disinhibition & $0.506^{*}$ & $0.491^{*}$ & $0.315^{*}$ & $0.357^{*}$ & $0.484^{*}$ \\
\hline Susceptibility to hunger & $0.560^{*}$ & $0.523^{*}$ & $0.418^{*}$ & $0.383^{*}$ & $0.546^{*}$ \\
\hline
\end{tabular}

${ }^{*} \mathrm{p}<0.01$. G-FCQ-T: General-Food Craving Questionnaire-Trait, DEBQ-C: Children's version of the Dutch Eating Behavior Questionnaire, TFEQ: Three-Factor Eating Questionnaire

Table 4. Summary of ROC analysis predicting food craving

\begin{tabular}{cccccc}
\hline & AUC & $95 \%$ CI & Cut-off & Sensitivity & Specificity \\
\hline G-FCQ-T & 0.917 & $0.856-0.978$ & 51.0 & 0.833 & 0.825 \\
\hline
\end{tabular}

AUC: area under the curve, CI: confidence interval, ROC: receiver operating characteristic

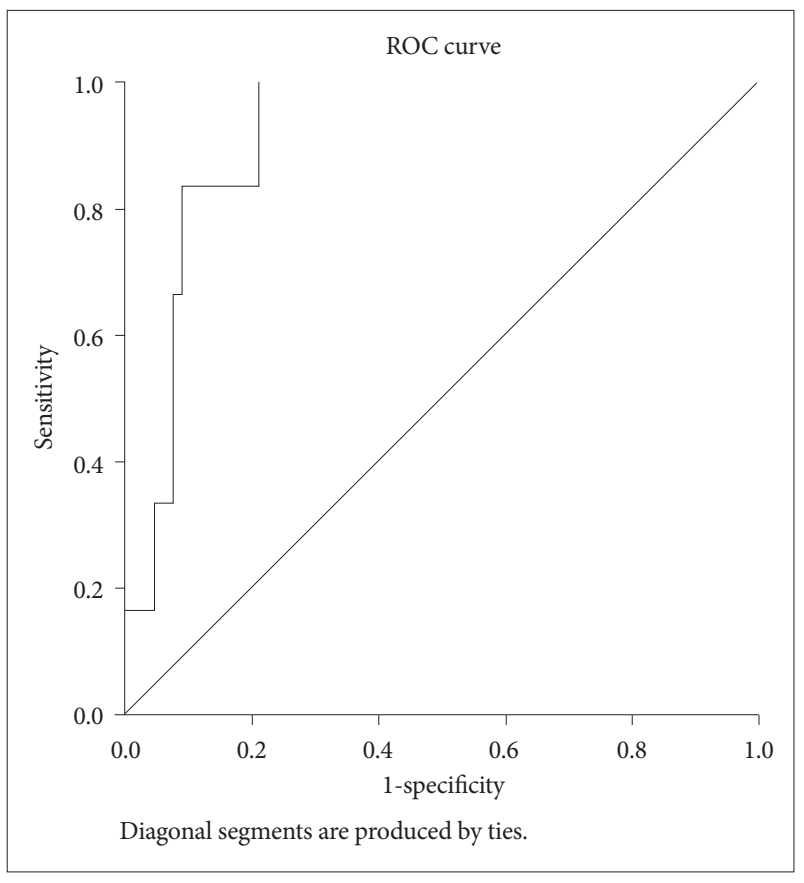

Figure 2. The ROC curve for the G-FCQ-T to predict food craving. ROC: receiver operating characteristic, G-FCQ-T: General-Food Craving Questionnaire-Trait.

ROC analysis (Table 4, Figure 2)

ROC analysis was applied to predict food craving. Sensitivity and specificity were calculated for G-FCQ-T scores relative to the sum of emotional and external eating scales of DEBQ$\mathrm{C}$ at the mean+2SD. The DEBQ-C was constructed using chil- dren ${ }^{18}$ and previous studies demonstrated that food cravers had significantly elevated external eating and emotional eating subscale scores on the DEBQ. 22,23 The AUC value was 0.917 (0.856-0.978), the cut-off value was 51 , sensitivity value was 0.833 , and specificity value was 0.825 . Applying the given cutoff point in the present sample, food cravers accounted for about $20 \%$ of the sample $(n=34)$.

\section{Exploratory factor analysis (Table 5)}

The Kaiser-Meyer-Olkin measure showed a value of 0.909 and Bartlett's test of sphericity was significant $(\mathrm{p}<0.001)$. The principal-components factor analysis on the items from the G-FCQ-T for all 172 subjects revealed that there were four factors that explained $65.61 \%$ of the total variance. Factor I explained $45.63 \%$ of the variance (eigenvalue, 9.58) and was construed as loss of control. Factor II (eigenvalue, 1.68) loaded on preoccupation with food. Factor III (eigenvalue, 1.48) loaded on positive outcome expectancy. Factor IV (eigenvalue, 1.04) loaded on negative emotional craving. However, question (Q) number 3 (Q3), Q8, and Q9 were classified in preoccupation with food, Q6 in positive outcome expectancy, and Q16 in negative emotional craving in the original version.

\section{DISCUSSION}

The current results suggest that the G-FCQ-T is a valid and reliable instrument for measuring food craving for children. The internal consistency and test-retest reliability were satis- 
Table 5. Exploratory factor analysis of the G-FCQ-T

\begin{tabular}{|c|c|c|c|c|}
\hline \multirow{2}{*}{ Question } & \multicolumn{4}{|c|}{ Factor } \\
\hline & I & II & III & IV \\
\hline 1. If I eat what I'm craving, I often lose control and eat too much & 0.806 & 0.148 & 0.153 & 0.201 \\
\hline 2. When I crave something, I know I won't be able to stop eating once I start & 0.705 & 0.217 & 0.275 & -0.010 \\
\hline 3. Food cravings always make me think of ways to get what I want to eat & 0.672 & 0.248 & 0.163 & 0.169 \\
\hline 4. If I get what I'm craving I cannot stop myself from eating it & 0.666 & 0.015 & 0.131 & 0.442 \\
\hline 5. Once I start eating, I have trouble stopping & 0.603 & 0.348 & 0.383 & 0.058 \\
\hline 6. Sometimes, eating make things seem just perfect & 0.556 & 0.182 & 0.354 & 0.358 \\
\hline 7. When I am with someone who is overeating, I usually overeat too & 0.552 & 0.458 & 0.093 & -0.053 \\
\hline 8. I find myself absorbed in food & 0.539 & 0.447 & 0.238 & 0.254 \\
\hline 9. Whenever I go to a buffet I end up eating more than what I needed & 0.457 & 0.257 & 0.444 & 0.081 \\
\hline 10. I spend a lot of time thinking about whatever it is I will eat next & 0.096 & 0.763 & 0.136 & 0.260 \\
\hline 11. I can't stop thinking about eating no matter how hard I try & 0.228 & 0.755 & 0.258 & 0.268 \\
\hline 12. If I am craving something, thoughts of eating it consume me & 0.285 & 0.748 & 0.160 & 0.088 \\
\hline 13. I feel like I have food on my mind all the time & 0.370 & 0.722 & 0.211 & 0.139 \\
\hline 14. I feel less anxious after I eat & 0.037 & 0.217 & 0.780 & 0.208 \\
\hline 15. When I eat food, I feel comforted & 0.148 & 0.200 & 0.777 & 0.208 \\
\hline 16. Eating what I crave makes me feel better & 0.219 & -0.015 & 0.708 & 0.249 \\
\hline 17. When I eat what I crave, I feel great & 0.289 & 0.211 & 0.685 & -0.074 \\
\hline 18. My feelings often make me want to eat & 0.328 & 0.178 & 0.650 & 0.110 \\
\hline 19. When I'm stressed out, I crave food & 0.257 & 0.251 & 0.195 & 0.801 \\
\hline 20. I crave foods when I'm upset & 0.116 & 0.528 & 0.185 & 0.702 \\
\hline 21. I crave foods when I feel bored, angry or sad & 0.254 & 0.493 & 0.398 & 0.503 \\
\hline
\end{tabular}

Rotation method: Varimax with Kaiser Normalization. Highest loadings, on the basis of which items are allocated to a factor, are printed in bold. G-FCQ-T: General-Food Craving Questionnaire-Trait

factory. The results of comparing the G-FCQ-T with DEBQ$\mathrm{C}$ or TFEQ also showed good validity and significant positive correlations between the G-FCQ-T and DEBQ-C or TFEQ scores. The optimum cutoff score of G-FCQ-T set by ROC analysis was 51 in children.

Consistent with our results, previous studies with young adults showed high internal consistency (Cronbach's alpha $=0.875-0.90$ ) and two- or three-week test-retest reliability $(\mathrm{r}=0.79-0.850)$ for the G-FCQ-T.2, Additionally, they showed significant positive correlations between the G-FCQ-T and adult version of the DEBQ $(r=0.23-0.492)$ or TFEQ $(r=0.435))^{2,21}$ These results implied that the G-FCQ-T has good psychometric properties for the assessment of food craving both in children and adults.

Furthermore, the present study also demonstrated the associations between the G-FCQ-T and DEBQ-C or TFEQ subscales. Significant positive correlations were shown between the G-FCQ-T scales and DEBQ-C emotional or external eating, and between the G-FCQ-T scales and the TFEQ disinhibition or susceptibility to hunger subscales. These subscales reflect a tendency toward disinhibited eating occurance along with food exposure, negative feelings, or subjective feelings of hun- ger. Although the DEBQ-C and TFEQ are measurements to assess not food craving but eating behavior, previous studies have shown associations between external, emotional eating, disinhibition, and susceptibility to hunger with strength and frequency of food craving similar to our results. ${ }^{3,22,24}$ That is the reason why the present authors deemed participants with scores exceeding the mean plus two standard deviations of the sum scores on the DEBQ-C emotional and external eating to be eligible for the group of high food cravers in the ROC analysis. We only used the DEBQ-C scores as a standard as it is a children-adapted scale, rather than the TFEQ ones. The cutoff score of the G-FCQ-T in the present study (a total score of 51) is a stricter criterion than that of another study ${ }^{6}$ that used scoring in the upper third (about a total score of 40 in the present study) to predict food craving.

According to exploratory factor analysis, the G-FCQ-T had a four-factor structure; the present authors interpreted the four factors as indicative of preoccupation with food, loss of control, positive outcome expectancy, and emotional craving as in the original version. However, it was not possible to reproduce the original factors of preoccupation with food and 
loss of control (Q 3, 5, and 17). These factors contain a mixture of questions on uncontrolled eating behavior, connected with thoughts or preoccupation with food. The reason for failure to replicate these two factors may be related to age differences of the participants. The original version of G-FCQ-T was developed in a sample of college students. An earlier study reported that thoughts preoccupied with food or craving and uncontrolled food consumption are tightly coupled in childhood but become less so with age. ${ }^{12}$ This finding implies that the link between preoccupation with food and lack of control over eating in children can be attributed to this mixed result in scale construction. In the case of Q6 and Q16 of the G-FCQ-T in our sample, the translation of these items might have underrepresented the meaning of how positive outcome expectancy or negative emotion influence food craving, and this may also have affected the scale construction. Therefore, further validation work in larger and independent samples of children is required.

Past research indicates that gender differences may be present in the characteristics of food craving, such as prevalence, affective state, or food selection during food craving. ${ }^{7.14} \mathrm{Com}$ pared to men, women were more likely to experience food craving and reported more emotional eating, and these differences were assumed to be related to hormonal differences.? In addition, another study showed a significant positive relationship between BMI and food craving ${ }^{25}$ and food-craving responses to food stimuli were related to measures of insulin resistance and thalamic brain activation in individuals with obesity compared to those of normal weight. ${ }^{1}$ In contrast to earlier findings, however, the results of the present study showed no differences in food craving between gender and BMI groups. These inconsistencies may be due to the ages of participants, since in our study, all participants were children, including premenarcheal girls.

This study has the following limitations. First, participants were limited to 5th grade elementary school students from one school of a specific region. Prior studies have noted developmental comfort food preferences ${ }^{26}$ and developmental changes in functional brain responses to images of foods. ${ }^{27}$ Second, we did not screen for psychiatric disorders especially eating disorders, or assess which phase of the menstrual cycle the female students were in. Several reports have shown that food craving was followed by binge eating, ${ }^{28}$ one of the features of eating disorders, and that menstrual cycle effects on eating occur independently. ${ }^{29,30}$ Therefore, the results need to be replicated in samples with various age groups, particularly adolescents, and in individuals with eating disorders. Third, the G-FCQ-T was developed in a sample of university students, not children. Although the present authors tried to modify the scale to adapt it to young students, and used the children's ver- sion of the DEBQ to evaluate construct validity, the original version of the G-FCQ-T was validated with young adults. Fourth, the DEBQ-C and TFEQ were not validated among Korean children or adolescents. However, the DEBQ-C and TFEQ were validated among 473 Spanish children aged 10 to 14 years ${ }^{31}$ and 769 Dutch children aged 7 to 12 years, ${ }^{18}$ and among 192 Spanish children aged 8.8 to 16.8 years ${ }^{32}$ respectively. Fifth, DEBQ-C scores, instead of a clinical diagnosis of food craving, were used in the ROC analysis because of the difficulty of confirming craving and lack of consensus about the definition of craving. Nevertheless, a cutoff point was obtained by applying relatively strict criteria, and this point may be useful to inform preliminary research and prompt decision to assess food craving. Sixth, we examined the test-retest reliability by performing the retest after a 1-month interval. Even though the time between the test and re-test in the present study was longer than that used in previous studies, ${ }^{2,21}$ we could not exclude the attribution of the learning effect by the participants. A faster learning rate has been reported when the retest time interval decreases. ${ }^{33}$ Therefore, longer test-retest intervals could reflect better test-retest reliability.

In spite of these limitations, this study suggests that the GFCQ-T has satisfactory psychometric properties in children. That is, the G-FCQ-T is a reliable and valid tool for assessing craving in children in Korea. Furthermore, this study also provided a cutoff score, which may assist clinicians in screening for high food cravers in children. When considering that childhood is a sensitive period for the acquisition of obesity and the association between food craving and obesity, this scale and cutoff point will provide new insights to approach the management of and predict susceptibility to overeating and obesity in children. More research is required to evaluate the G-FCQ-T, including confirmatory factor analysis and studies applying to a wide range of age groups.

\section{Acknowledgments}

This research was supported by the Brain Research Program through the National Research Foundation of Korea (NRF) funded by the Ministry of Science, ICT \& Future Planning (NRF-2013M3C8A2A02078508).

\section{REFERENCES}

1. Potenza MN, Grilo CM. How relevant is food craving to obesity and its treatment? Front Psychiatry 2014;5:164.

2. Nijs IM, Franken IH, Muris P. The modified trait and state food-cravings questionnaires: development and validation of a general index of food craving. Appetite 2007;49:38-46.

3. Gilhooly CH, Das SK, Golden JK, McCrory MA, Dallal GE, Saltzman E, et al. Food cravings and energy regulation: the characteristics of craved foods and their relationship with eating behaviors and weight change during 6 months of dietary energy restriction. Int J Obes (Lond) 2007;31:1849-1858.

4. Flint A, Raben A, Blundell JE, Astrup A. Reproducibility, power and validity of visual analogue scales in assessment of appetite sensations 
in single test meal studies. Int J Obes Relat Metab Disord 2000;24:38-48.

5. Martin CK, O'Neil PM, Tollefson G, Greenway FL, White MA. The association between food cravings and consumption of specific foods in a laboratory taste test. Appetite 2008;51:324-326.

6. Brockmeyer T, Hahn C, Reetz C, Schmidt U, Friederich HC. Approach bias and cue reactivity towards food in people with high versus low levels of food craving. Appetite 2015;95:197-202.

7. Imperatori C, Innamorati M, Tamburello S, Continisio M, Contardi A, Tamburello A, et al. Gender differences in food craving among overweight and obese patients attending low energy diet therapy: a matched case-control study. Eat Weight Disord 2013;18:297-303.

8. Delahanty LM, Meigs JB, Hayden D, Williamson DA, Nathan DM; Diabetes Prevenion Program (DPP) Research Group. Psychological and behavioral correlates of baseline $\mathrm{BMI}$ in the diabetes prevention program (DPP). Diabetes Care 2002;25:1992-1998.

9. Burrows T, Meule A. 'Food addiction'. What happens in childhood? Appetite 2015;89:298-300.

10. Galvan A, McGlennen KM. Enhanced striatal sensitivity to aversive reinforcement in adolescents versus adults. J Cogn Neurosci 2013;25: 284-296.

11. Kober H, Mende-Siedlecki P, Kross EF, Weber J, Mischel W, Hart CL, et al. Prefrontal-striatal pathway underlies cognitive regulation of craving. Proc Natl Acad Sci U S A 2010;107:14811-14816.

12. Silvers JA, Insel C, Powers A, Franz P, Weber J, Mischel W, et al. Curbing craving: behavioral and brain evidence that children regulate craving when instructed to do so but have higher baseline craving than adults. Psychol Sci 2014;25:1932-1942.

13. Nederkoorn C, Smulders FT, Jansen A. Cephalic phase responses, craving and food intake in normal subjects. Appetite 2000;35:45-55.

14. Rodriguez-Martin BC, Meule A. Food craving: new contributions on its assessment, moderators, and consequences. Front Psychol 2015;6:21.

15. Cepeda-Benito A, Gleaves DH, Williams TL, Erath SA. The development and validation of the state and trait food-cravings questionnaires. Behav Ther 2000;31:151-173.

16. Batra P, Das SK, Salinardi T, Robinson L, Saltzman E, Scott T, et al. Relationship of cravings with weight loss and hunger. Results from a 6 month worksite weight loss intervention. Appetite 2013;69:1-7.

17. Dietz WH. Critical periods in childhood for the development of obesity. Am J Clin Nutr 1994;59:955-959.

18. van Strien T, Oosterveld P. The children's DEBQ for assessment of restrained, emotional, and external eating in 7 - to 12 -year-old children. Int J Eat Disord 2008;41:72-81.
19. Cole TJ, Bellizzi MC, Flegal KM, Dietz WH. Establishing a standard definition for child overweight and obesity worldwide: international survey. BMJ 2000;320:1240-1243.

20. Stunkard AJ, Messick S. The three-factor eating questionnaire to measure dietary restraint, disinhibition and hunger. J Psychosom Res 1985; 29:71-83.

21. Noh JH, Kim JH, Nam HJ, Lim MR, Lee DS, Hong KS. Validation of the Korean version of the General Food Cravings Questionnaire-Trait (G-FCQ-T). Korean J Clin Psychology 2008;27:1039-1051.

22. Hill AJ, Weaver CF, Blundell JE. Food craving, dietary restraint and mood. Appetite 1991;17:187-197.

23. Tuomisto T, Hetherington MM, Morris MF, Tuomisto MT, Turjanmaa V, Lappalainen R. Psychological and physiological characteristics of sweet food "addiction". Int J Eat Disord 1999;25:169-175.

24. Rogers PJ, Smit HJ. Food craving and food "addiction": a critical review of the evidence from a biopsychosocial perspective. Pharmacol Biochem Behav 2000;66:3-14.

25. Chao A, Grilo CM, White MA, Sinha R. Food cravings, food intake, and weight status in a community-based sample. Eat Behav 2014;15:478-482.

26. Wansink B, Cheney MM, Chan N. Exploring comfort food preferences across age and gender. Physiol Behav 2003;79:739-747.

27. Killgore WD, Yurgelun-Todd DA. Developmental changes in the functional brain responses of adolescents to images of high and low-calorie foods. Dev Psychobiol 2005;47:377-397.

28. Waters A, Hill A, Waller G. Bulimics' responses to food cravings: is binge-eating a product of hunger or emotional state? Behav Res Ther 2001;39:877-886.

29. Cohen IT, Sherwin BB, Fleming AS. Food cravings, mood, and the menstrual cycle. Horm Behav 1987;21:457-470.

30. Bancroft J, Cook A, Williamson L. Food craving, mood and the menstrual cycle. Psychol Med 1988;18:855-860.

31. Banos RM, Cebolla A, Etchemendy E, Felipe S, Rasal P, Botella C. Validation of the Dutch Eating Behavior Questionnaire for Children (DEBQ-C) for use with Spanish children. Nutr Hosp 2011;26:890-898.

32. Martín-García M, Vila-Maldonado S, Rodríguez-Gómez I, Faya FM, Plaza-Carmona M, Pastor-Vicedo JC, et al. The Spanish version of the Three Factor Eating Questionnaire-R21 for children and adolescents (TFEQ-R21C): psychometric analysis and relationships with body composition and fitness variables. Physiol Behav 2016;165:350-357.

33. Lemay S, Bedard MA, Rouleau I, Tremblay PL. Practice effect and testretest reliability of attentional and executive tests in middle-aged to elderly subjects. Clin Neuropsychol 2004;18:284-302. 